\title{
Relationship between testosterone supplementation and insulin-like growth factor-I levels and cognition in healthy older men
}

\author{
M.M. Cherrier ${ }^{\mathrm{a}, \mathrm{c}, *}$, S. Plymate ${ }^{\mathrm{b}, \mathrm{c}}, \mathrm{S}$. Mohan ${ }^{\mathrm{e}}$, S. Asthana ${ }^{\mathrm{c}}$, \\ A.M. Matsumoto ${ }^{\mathrm{b}, \mathrm{c}}, \mathrm{W}$. Bremner ${ }^{\mathrm{b}}$, E. Peskind ${ }^{\mathrm{a}, \mathrm{c}, \mathrm{d}}$, \\ M. Raskind ${ }^{\text {a,c,d }}$, S. Latendresse ${ }^{c}$, A.P. Haley ${ }^{c}$, S. Craft ${ }^{\text {a,c }}$ \\ a Department of Psychiatry and Behavioral Sciences, University of Washington Medical School, \\ 1959 NE Pacific, Box 356560, Seattle, WA 98195, USA \\ ${ }^{\mathrm{b}}$ Department of Medicine, University of Washington Medical School, Seattle, WA, USA \\ ${ }^{\mathrm{c}}$ Geriatric Research, Education and Clinical Center, Veterans Administration Puget Sound Health \\ Care System, Seattle, WA 98108, USA \\ ${ }^{\mathrm{a}}$ Mental Illness Research, Education and Clinical Center, Veterans Administration Puget Sound \\ Health Care System, Seattle, WA 98108, USA

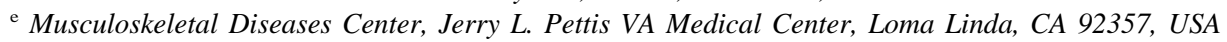

Received 21 May 2002; received in revised form 24 September 2002; accepted 24 October 2002

\begin{abstract}
Background. Our laboratory has previously reported that testosterone (T) administration to older men significantly improves cognitive function. This study examined potential changes in insulin-like growth factor (IGF) IGF-I, IGF-II and IGF-related binding proteins in response to $\mathrm{T}$ administration in older men and their relationship to cognitive functioning.

Methods. Twenty-five healthy community dwelling volunteers, ranging in age from 50-80 years were randomized to receive weekly intra-muscular (i.m.) injections of either $100 \mathrm{mg} \mathrm{T}$ enanthate or placebo (saline) for 6 weeks. Serum hormone levels and cognitive functioning was assessed at baseline and twice during treatment.

Results. Significant positive associations between IGF-I and IGF-II and spatial memory, spatial reasoning, and verbal fluency were observed after 6 weeks of $\mathrm{T}$ administration. Increased serum $\mathrm{T}$ levels from treatment were positively associated with improvement in spa-
\end{abstract}

\footnotetext{
* Corresponding author. Tel.: +1-206-685-8704; fax: +1-206-221-5130.
}

E-mail address: cherrier@u.washington.edu (M.M. Cherrier). 
tial reasoning performance, whereas estradiol was associated with a decline in divided attention performance. Serum IGF-I, IGF-II and IGFBPs did not change in response to T treatment.

Conclusions. Our results suggest that T, estradiol and IGF-I may have independent and selective effects on cognitive functioning. Positive associations between $\mathrm{T}$ levels and cognition are consistent with an effect of androgen treatment, whereas positive associations between IGF-I levels and cognition are reflective of a relationship between endogenous IGF-I levels and cognition.

(C) 2003 Elsevier Ltd. All rights reserved.

Keywords: Neuroendocrinology; Neuropsychology; Androgens; Testosterone; Insulin-like growth factor-1; Aging; Cognition

\section{Introduction}

Insulin-like growth factors (IGFs) play an important role in neural development and function, and they are also involved in local regulation of a number of tissues. Aging results in a reduced secretion of growth hormone $(\mathrm{GH})$ and production of insulin-like growth factor-1 (IGF-I) and this contributes to altered metabolic changes and body composition in aging. Decreased IGF-I levels are associated with impaired protein synthesis, decreased lean and increased fat body mass, and diminished bone density (Benbassat et al., 1997; Morley et al., 1997; Rollero et al., 1998).

IGF's may have an important role in cognitive functioning. IGF-I and IGF-II in the brain stimulate DNA and RNA synthesis, neurite formation, rates of protein synthesis, synaptogenesis, calcium regulation, neuronal repair and survival of neurons and glia in culture all of which have potential effects on cognitive function (D’Costa et al., 1995; Han et al., 1988; Ishii, 1989; Ishii et al., 1994; McMorris and Dubois-Dalcq, 1988; Recio-Pinto et al., 1986). IGF-I and IGF-II regulate acetylcholine (Ach) measured from hippocampal neurons and cortical slices (Kar et al., 1997). Aging results in reduced IGF-I protein levels and receptor density with the most dramatic decline in the hippocampus, and IGF-I administration improves learning and increases neuronal regeneration in animals with induced neuronal damage (Lai et al., 1993, 2000; Saatman et al., 1997; Sonntag et al., 1997; van Dam et al., 2000).

In humans, serum IGF-I correlates positively with mini-mental status examination (MMSE) scores, visual and verbal memory, fluid intelligence and sensitive measures of information processing or working memory in healthy older men, whereas serum levels of GH do not (Aleman et al., 1999, 2000, 2001; Morley et al., 1997; Rollero et al., 1998; van Dam et al., 2000). Declines in total IGF-I and IGF-I/IGFBP-3 ratio have also been reported to correlate significantly with declines in MMSE (Kalmijn et al., 2000).

Recently, it has been shown that IGF-I receptors may be regulated in part by the androgen receptor (AR) (Gori et al., 1999; Russo et al., 1999; Vendola et al., 1999). Testosterone (T) administration has been reported to increase serum IGF-I levels in both young and older men (Ferrando et al., 2002; Hobbs et al., 1993; Veldhuis et al., 1997; Weissberger and Ho, 1993). Although studies examining the effects of T supplementation on cognition have been mixed, several studies have reported ben- 
eficial effects of $\mathrm{T}$ on verbal and spatial memory, and verbal fluency in healthy older and younger men (Cherrier et al., 2001; Janowsky et al., 1994, 2000; O'Connor et al., 2001; Sih et al., 1997; Wolf et al., 2000).

In this study, we performed additional IGF and IGFBP hormone assays on serum samples from a previous study that examined the effects of $\mathrm{T}$ supplementation on cognition. Results of the cognitive changes in response to $\mathrm{T}$ supplementation have been reported elsewhere (Cherrier et al., 2001). The purpose of this study was to examine whether $\mathrm{T}$ supplementation resulted in changes in IGF-I, IGF-II and related IGFBP levels in a population of older men. A second aim of this study was to determine the relationship between changes in cognitive functioning and hormone levels. We hypothesized that $\mathrm{T}$ administration would increase IGF-I and IGF-II levels and that increases in IGF-I and IGF-II would demonstrate a positive association with memory measures due to IGF-I and IGF-II effects on brain Ach levels.

\section{Methods}

\subsection{Participants}

This study was approved by the University of Washington Institutional Review Board, and approved informed consent procedures were followed. As detailed in Cherrier et al. (2001), participants were healthy older men between the ages of 50 and 80 years, recruited from the community through flyers. Seventy-seven potential participants who responded to posted flyers were given a brief phone screen. Eligible participants were asked to undergo a clinical screening visit including a thorough physical, psychiatric and laboratory evaluation to exclude any significant physical or medical illness. This included tests of renal and hepatic function, hypertension, and prostate disease (prostate specific antigen (PSA) level, and digital rectal exam (DRE)). Participants with abnormal findings were excluded from the study. Participants also underwent a cognitive screening examination consisting of the MMSE and the Mattis Dementia Rating Scale (DRS) to ensure that participants were within the normal range for their age (Folstein et al., 1975; Mattis, 1988). Participants with scores at or below the recommended cut-off score (MMSE $<26$ or DRS $<130$ ), or history of significant alcohol abuse, psychiatric illness, head injury with loss of consciousness, current use of medications with any central nervous system effects or medications such as cimetidine which block the AR were excluded. Participants with previous or current prostate cancer, elevated PSA levels, history of myocardial infarction, abnormal renal or hepatic disease, sleep apnea, previous T treatment, or other gonadal endocrine disorders were also excluded.

\section{Procedures}

\subsection{Study design}

As described in Cherrier et al. (2001), subjects were randomly assigned to the treatment or placebo group. Subjects and psychometrists who performed the cogni- 
tive testing and investigators were blind to treatment condition. Nurses who administered the injections were not blind and were responsible for preparing syringes in advance to ensure a blind condition for subjects.

Twenty-five healthy older men who met screening criteria reported to the Special Studies Unit of the Veterans Administration Puget Sound Health Care System (VAPSHCS) for weekly intramuscular (i.m.) injections of $100 \mathrm{mg} \mathrm{T}$ enanthate (Delatestryl, manufactured for BTG Pharmaceuticals Corporation by Bristol-Myers Squibb, Princeton, NJ) or placebo (saline). Dosage of $\mathrm{T}$ was designed to increase serum $\mathrm{T}$ levels into the normal or high normal range of healthy young men. At these weekly visits, blood samples were taken for hormone levels. Cognitive testing was conducted at baseline and repeated at weeks 3 and 6 of treatment. Testing sessions occurred within 24-48 h following $\mathrm{T}$ or placebo injection to capture peak $\mathrm{T}$ levels for the treated group; therefore cognitive performance results reflect the effects of peak $\mathrm{T}$ levels. Thirteen participants were randomized into the treatment and 12 participants were randomized into the placebo control group. The treatment and placebo groups did not differ on demographic variables (age and education) with an overall mean of $15.5( \pm 3)$ years of education and $67.5( \pm 8)$ years of age for all participants. The groups were cognitively intact with no significant differences on the DRS with an overall mean score of $140( \pm 3.5)$. Endogenous T levels measured at baseline, prior to the start of the study were in the normal range for healthy older men (15$20 \mathrm{nmol} / \mathrm{l})$ and were not significantly different between groups ( $\mathrm{T}$ group $=20( \pm$ 6) $(\mathrm{nmol} / \mathrm{l})$; control group $19( \pm 7)(\mathrm{nmol} / \mathrm{l}))$. The normal range for young men is $22( \pm 4) \mathrm{nmol} / \mathrm{l}$ (Matsumoto, 1996). PSA levels were measured at screen, week 4 of the study and again at washout. Mean PSA level was $1.54( \pm 0.62) \mathrm{ng} / \mathrm{ml}$ for all participants at the start of the study. PSA in all subjects was within normal limits (0-4 ng/ml).

\subsection{Cognitive Battery}

A comprehensive battery of cognitive tests was constructed to assess spatial ability, spatial and verbal memory, verbal fluency and attention. Spatial ability and spatial memory measures were included based on findings from previous studies in older men suggesting a beneficial effect of androgens on these cognitive abilities (Janowsky et al., 1994, 2000). A measure of verbal fluency was included based on a previous study indicating improved verbal fluency from androgen supplementation in hypogonadal men (Alexander et al., 1998). Measures of verbal memory and divided attention were also included to assess whether verbal memory would change from androgen administration. Comparable, alternate versions of each test were administered at each time point. Psychometrists and participants were blind to the treatment condition.

\subsubsection{Spatial memory}

Route test: The task used a $6 \times 24 \mathrm{ft}$ piece of black flooring with a permanent diamond grid pattern indicated by yellow tape. The examiner created a particular route on the grid using a red ribbon. The subject was asked to walk the route as 
shown. The ribbon was removed, and the subject was asked to immediately retrace the route without the ribbon. Three trials were administered followed by three trials of a new route using picture landmarks placed on the floor. Performance was assessed by calculating the number of correct sequential units summed across all trials for a total of 66 possible points. This test has been shown to have good reliability in both young and old populations and validity when compared to other route tests and in comparison of brain injured and controls (Barrash and Tranel, 1996).

\subsubsection{Verbal memory}

Story recall: The story recall task was modeled on the Wechsler Memory ScaleRevised and measured memory for aurally presented contextual material. Participants listened to two brief narratives, each containing 25 informational bits, and were asked to recall as much as possible immediately after hearing each story and following a 20-min delay (Wechsler, 1987). Total number of words recall from both stories was summed for immediate and delayed recall. Delayed recall was divided by immediate recall to obtain a savings score or a percent of information retained. Reliability and validity of WMS-R and WMS-III Logical Memory, and this modified version are very good (Craft et al., 1992, 1993, 1994; Wechsler, 1987, 1997b).

\subsubsection{Spatial ability}

Block design: This test is based on the Wechsler Adult Intelligence Scale-Revised, Block design subtest and measures participants' ability to analyze and construct abstract figures from their component parts (Wechsler, 1981). The subject is shown individual, red and white designs on paper and asked to construct the design using nine three-dimensional blocks with red and white sides. Time to completion is recorded for each design, with an upper limit of 3 min per design. There are nine total designs, with three designs per difficulty level (easy, moderate and hard). Total time for designs was summed for analysis. Reliability and validity of the WAIS-III Block Design subtest are well established (Wechsler, 1997a).

\subsubsection{Divided attention measure}

Stroop color word interference task. This task is based on the original Stroop test (Stroop, 1935). The first condition (word reading) required participants to read a list of words as quickly as possible. The second condition required naming blocks of colored ink out loud as quickly as possible. The third condition (color word interference) required participant to name the ink color of the printed words (stimuli consist of color names that are printed in discordant colors, e.g. the word 'blue' printed in green letters). Total time for each trial is recorded, and time to complete the third trial was used for analysis. The test has demonstrated good reliability and validity when examined in closed head injured individuals compared to controls (Lezak, 1995).

\subsubsection{Verbal fluency}

Participants were asked to generate verbally as many words beginning with a particular letter (e.g. 'P') within a 60 s period (Spreen and Strauss, 1991). Two trials 
were administered with two different letters. The total number of words generated was recorded for each letter and summed. Test-retest reliability in an older population is good $(0.70,0.71)$ and validity studies using factor analysis suggest that it loads on a factor of abstract mental operation and language (Lezak, 1995; Snow et al., 1988).

\subsubsection{Hormone assays}

Hormone levels were drawn immediately following cognitive testing, which occurred 24-48 h following injection. Thus serum hormone levels represent a peak value. Samples were kept frozen at $-70^{\circ}$ until the completion of the study when all samples were assayed. Serum estradiol and total $\mathrm{T}$ levels were analyzed with radioimmunoassay (RIA) according to standard procedures for each commercial kit. $\mathrm{T}$ assays were run with a DELFIA T kit (Wallac OY, MD) with a sensitivity of 0.5 $\mathrm{nmol} / \mathrm{l}$ and $4.5 \%$ intra-assay variability. The $17 \beta$-estradiol was measured with the ImmunuChem double antibody kit (ICN Biomedicals, Inc., CA) with $36.7 \mathrm{pmol} / 1$ sensitivity and 6.8 intra-assay variability. All samples from each individual were run in duplicate in the same assay to avoid inter-assay variability. Hormone levels reported were the average of the duplicate samples.

Total IGF-I and IGF-II were measured rather than free IGF-I as these have demonstrated significant associations with cognition in previous studies, and free IGF-I has failed to demonstrate an association (Kalmijn et al., 2000; Rollero et al., 1998). IGFI and IGF-II were measured by RIA after separation of IGFBPs, as described previously (Mohan and Baylink, 1995). The separation of the IGFBPs from IGFs was achieved by a rapid acid gel-filtration protocol, described previously (Mohan and Baylink, 1995). To measure serum levels of IGFBP-3, IGFBP-4 and IGFBP-5, we used RIA validated by one of the authors (S.M.) using recombinant human IGFBP3, IGFBP-4 and IGFBP-5 as antigens tracer and standard (Honda et al., 1996; Mohan et al., 1995). Each of the IGFBP RIAs was specific and no cross-reactivity was seen between the IGFBPs.

\subsection{Statistical analyses}

To assess differences between the $\mathrm{T}$ and placebo group during two on-treatment time-points for hormone measures, repeated measures of multivariate analysis of variance (MANOVA) was used with group as the independent factor ( $\mathrm{T}$ versus placebo) and weeks (baseline, and weeks 3 and 6) as the repeated factor, total $\mathrm{T}$, estradiol, IGF-I, IGF-II and IGFBP3-6 as dependent measures. IGF-I, IGF-2 and IGFBP3-6 levels were log-transformed to achieve a more homoscedastic distribution of data points. This is a commonly accepted numerical transformation, and frequently used with IGF and related binding protein data (Benbassat et al., 1997; Mohan and Baylink, 1997).

To examine several hormone measures (total T, estradiol, IGF-I, IGF-II and IGFBP3-6) as independent variables and their relationship with several cognitive measures (spatial memory, spatial abilities, verbal memory, verbal fluency and attention) as dependent measures, canonical correlation analyses were performed for 
the corresponding sets of cognitive measures and serum hormone values at baseline and weeks 3 and 6 of treatment. Canonical correlation is the optimal method to examine the relationship between multiple dependent and independent variables while controlling for the family wise error rate associated with multiple individual correlations (Tabachnik and Fidell, 1986). A canonical correlation is similar to multiple regression, except that instead of several variables predicting one variable, there are numerous variables on both sides of the equation. Variables in the equation included endocrine measures (total T, estradiol, IGF-I, IGF-II and IGFBP3-6) and cognitive measures (spatial memory, spatial abilities, verbal memory, verbal fluency and attention). Canonical variates consisted of linear combinations of the independent variables (endocrine measures) and the dependent variables (cognition). The best combination of independent and dependent variables from each side of the equation that resulted in a reliable prediction, resulted in a pair of canonical variates. Typically, a canonical variate score of 0.30 or above is accepted as an indication of a reliable and interpretable variable (Tabachnik and Fidell, 1986). Due to our limited sample size, we used a conservative cut-off value of 0.35 . All data were included in the analysis, with no exclusion of outliers. Both treated and non-treated participants were included in the analysis. Canonical analysis, like regression analysis requires that variables used in the analysis meet the assumption of a wide range values (rather than a restricted range), therefore, both treated and non-treated participants were used in the analysis.

After significant relationships between hormone levels and cognitive measures were revealed using canonical correlation analyses, subsequent regression analyses were performed on hormone and cognition measures for changes from baseline scores. The purpose of additional regression analyses was to examine the predictive power of change in serum hormone levels in relation to change in cognitive functioning. Stepwise hierarchical regression analyses were conducted for change from baseline scores at week 6 for the Route test, Story recall, Block design, Stroop task, and Verbal fluency as dependent variables and change from baseline for T, estradiol, IGF-I, IGF-II and years of education as independent variables. Cognitive variables were not combined to form one dependent variable as the cognitive processes measured by these tests are differentially effected by hormone manipulation (Cherrier et al., 2001; Janowsky et al., 1998, 2000). Change scores were calculated by subtracting baseline from week 6 data values. Regression analysis of hormone and cognitive variables were not conducted for data at week 3 as the canonical correlation analysis for that time point was non-significant. Regression analysis for baseline was not included as baseline data were used to produce change scores. All statistical analyses were performed using SPSS for Windows 9.0 (SPSS, 1998).

\section{Results}

Repeated measures MANOVA with group as the independent factor ( $\mathrm{T}$ versus placebo) and weeks (baseline, weeks 3 and 6) as the repeated factor and total T, estradiol, IGF-I, IGF-II and IGFBP3-6 as dependent measures revealed a significant 
omnibus multivariate within subjects interaction effect $(F(5,16)=21.3, p<0.01)$. Subsequent examination of individual dependent measures revealed significant univariate interaction effect for total $\mathrm{T}(F(2,40)=36.7, p<0.01)$, total estradiol $(F(2,40)=11.3, p<0.01)$ and IGF-I $(F(2,40)=3.8, p<0.05)$. T treatment significantly increased serum $\mathrm{T}$ levels in the treatment group compared to the placebo group at weeks 3 and $6(F(1,20)=77.7, p<0.01 ; F(1,20)=45.7, p<0.01$, respectively) and compared to baseline at weeks 3 and $6(F(1,20)=72.2, p<$ $0.01 ; F(1,20)=48, p<0.01$, respectively). T treatment significantly increased serum estradiol levels in the treatment group compared to the placebo group at weeks 3 and $6(F(1,20)=19.9, p<0.01 ; F(1,20)=14.6, p<0.01$, respectively $)$ and compared to baseline at weeks 3 and $6(F(1,20)=17.7, p<0.01 ; F(1,20)=12.6, p$ $<0.01$, respectively). Serum IGF-I levels evidenced a significant interaction effect at weeks 3 and $6(F(1,20)=6.6, p<0.05 ; F(1,20)=4.7, p<0.05$, respectively $)$. This interaction effect was due to a slight decline in IGF-I levels for the placebo group and an increase for the treatment group. However, the increase in the treatment group and decrease in the placebo group were not significantly different from baseline. There were no significant differences between groups at baseline for $\mathrm{T}$, estradiol, IGF-I, IGF-II or IGFBPs. No significant differences between group, interaction effect or change over time was found for IGF-II or related binding proteins IGFBP3-6 (Table 1).

Table 1

Mean serum total T, estradiol, IGF-I, IGF-II and IGFBP3-6 values for treatment and placebo groups at baseline and on treatment (weeks 3 and 6)

\begin{tabular}{|c|c|c|c|c|}
\hline & $\begin{array}{l}\text { Treatment group } \\
\text { (mg/week) }\end{array}$ & Baseline & Week 3 & Week 6 \\
\hline & & Mean (s.d.) & Mean (s.d.) & Mean (s.d.) \\
\hline \multirow[t]{2}{*}{ Testosterone (nmol/l) } & T 100 & $20(7)$ & $44(6) * *$ & $43(8) * *$ \\
\hline & Placebo & $18(6)$ & $18(8)$ & $19(9)$ \\
\hline \multirow[t]{2}{*}{ Estradiol (pmol/l) } & T 100 & $118(29)$ & $222(93) * *$ & $213(100) * *$ \\
\hline & Placebo & $98(20)$ & $93(22)$ & $91(34)$ \\
\hline \multirow[t]{2}{*}{ IGF-I (ng/ml) } & T 100 & $161(70)$ & 188 (109) & $186(106)$ \\
\hline & Placebo & $197(84)$ & $195(87)$ & $182(57)$ \\
\hline \multirow[t]{2}{*}{ IGF-II (ng/ml) } & T 100 & 446 (129) & $517(182)$ & $568(183)$ \\
\hline & Placebo & 525 (137) & 448 (129) & $516(174)$ \\
\hline \multirow[t]{2}{*}{ IGFBP-3 (ng/ml) } & T 100 & $2672(631)$ & $2598(642)$ & $2596(614)$ \\
\hline & Placebo & $2882(695)$ & 2321 (479) & $2482(570)$ \\
\hline \multirow[t]{2}{*}{ IGFBP-4 ng/ml } & T 100 & $386(94)$ & $442(95)$ & 447 (117) \\
\hline & Placebo & $441(78)$ & $400(102)$ & $390(92))$ \\
\hline \multirow[t]{2}{*}{ IGFBP-5 ng/ml } & T 100 & $308(100)$ & $302(86)$ & $325(58)$ \\
\hline & Placebo & $320(37)$ & 307 (89) & $309(75)$ \\
\hline \multirow[t]{2}{*}{ IGFBP-6 ng/ml } & T 100 & $603(103)$ & $643(226)$ & 587 (139) \\
\hline & Placebo & $604(135)$ & $610(111)$ & $635(111)$ \\
\hline
\end{tabular}

$\mathrm{T}$ and estradiol levels represent peak serum levels (24-48 $\mathrm{h}$ after $\mathrm{T}$ injection). Asterisks indicate significant change from baseline. $* * p<0.01$. 
Canonical correlation analyses between endocrine variables (total $\mathrm{T}$, estradiol, IGF-I, IGF-II and IGFBP3-6) and cognitive variables (Route test, Block design, story recall, verbal fluency and Stroop test) were examined. For all cognitive variables, higher scores indicated better performance on the task with the exception of Block design and Stroop test in which a lower score indicated better performance. Canonical analysis at baseline and week 3 were non-significant. Canonical correlation analysis between endocrine variables and cognitive variables at week 6 were significant. The first canonical correlation was 0.89 (20\% overlapping variance), the second was 0.87 (20\% overlapping variance) and the remaining three canonical correlations were effectively zero. With all canonical correlations included $(F(40,46)=1.85, p$ $<0.05)$, and with the first canonical correlation removed $(F(28,41)=1.82, p<$ $0.05)$, subsequent $F$-tests were not significant. The first two pairs of canonical variates, therefore, accounted for the significant relationships between the two sets of variables. Data on the first two pairs of variables appear in Table 2. Table 2 contains the correlations between the independent and dependent variables and the canonical variates, standardized canonical variate coefficients, within-set variance accounted for by the canonical variates (percent of variance), redundancies, and canonical correlations. Total percent of variance and redundancy indicate that both pairs of canonical variates were moderately related.

Using a conservative cut-off score of 0.35 , estradiol was the only variable in the endocrine set that was correlated with the first canonical variate. Among the cognitive variables, verbal memory (paragraph recall) and divided attention (Stroop) correlated with the first canonical variate. The first pair of canonical variates indicates that higher levels of estrogen presumably secondary to aromatization from $\mathrm{T}(-0.69)$ was associated with better performance on a measure of verbal memory $(-0.46)$, but poor performance on a measure of divided attention or executive function $(-0.90)$.

The second canonical variate in the endocrine set was composed of estradiol, IGFI, IGF-II, IGFBP4 and IGFBP6, while the corresponding canonical variate from the cognitive set was composed of spatial memory (route), verbal memory (paragraph recall), spatial ability (Block design) and verbal fluency. Taken as a pair, these variates suggest that lower levels of estradiol $(-0.38)$ and increasing levels of IGF-I $(0.36)$ and IGF-II (0.62) along with lower levels of IGFBP4 $(-0.44)$ and IGFBP6 $(-0.72)$ are associated with better spatial memory $(0.71)$, better verbal memory for estradiol and IGFBP6 ( -0.44$)$, better constructional/spatial ability $(0.43)$ and better verbal fluency (0.45). The canonical correlation analysis revealed considerable redundancy (i.e. overlap) between the endocrine and cognitive measures suggesting that significant relationships between these hormone and cognitive measures may be accounted for by fewer measures. This is also supported by significant high correlations between IGF-I, IGF-II and the IGFBPs (Fig. 1).

Stepwise regression analyses were performed on change from baseline values to examine the predictive power of change in serum hormone levels in relation to change in cognitive functioning. An evaluation of assumptions for individual regression analyses on change score variables revealed skewed distributions as expected. Square root and log transformations were used for $\mathrm{T}$ and estradiol change from baseline scores to reduce skewness and improve the normality, linearity and 







\begin{tabular}{|l|c|l|l|l|l|l|l|}
\hline & IGF-I & IGF-II & $\begin{array}{l}\text { IGFBP- } \\
\mathbf{3}\end{array}$ & $\begin{array}{l}\text { IGFBP- } \\
\mathbf{1}\end{array}$ & $\begin{array}{l}\text { IGFBP- } \\
\mathbf{5}\end{array}$ & $\begin{array}{l}\text { IGFBP- } \\
6\end{array}$ & Testosterone \\
\hline IGF-I & & & & & & & \\
\hline IGF-II & $0.81^{* *}$ & & & & & & \\
\hline IGFBP-3 & $0.84^{* *}$ & $0.80^{* *}$ & & & & & \\
\hline IGFBP-4 & 0.28 & 0.03 & 0.08 & & & & \\
\hline IGFBP-5 & $0.41^{*}$ & 0.37 & $0.48^{*}$ & 0.10 & & & \\
\hline IGFBP-6 & -0.28 & -0.33 & -0.34 & 0.16 & $-0.43^{*}$ & & \\
\hline Testosterone & 0.04 & -0.19 & -0.15 & -0.27 & -0.03 & 0.05 & \\
\hline Estradiol & 0.01 & -0.29 & -0.18 & -0.04 & -0.05 & 0.25 & $0.80^{* *}$ \\
\hline
\end{tabular}

Fig. 1. Pearson product moment correlation table for IGF-I, IGF-II and IGFBP3-6 during treatment period (weeks 3 and 6 averaged) for all subjects, $N=25$. Significant correlations are indicated as follows: $* *$ correlation is significant at the 0.01 level (two tailed), *correlation is significant at the 0.05 level (two tailed).

homoscedacity of residuals. Stepwise regression analyses with the independent variables of (square root) T, (log) estradiol, IGF-I and IGF-II change from baseline were significant for change from baseline dependent variable scores of Stroop (time to complete interference trial), Block design (time to complete all designs) and Route test (correct sequence recall score). Regression analyses were non-significant for story recall and verbal fluency change from baseline.

For the dependent variable of Block design change from baseline score, $R$ was significantly different from zero after entry of two independent variables, (square root) $\mathrm{T}$ and $(\log )$ estradiol $F(2,22)=9.96, p<0.001$, which explained $49 \%$ of the variance. The first step of the regression model entered (square root) $\mathrm{T} R^{2}=$ $0.238, F_{\text {inc }}(1,21)=6.55, p<0.01$, which accounted for $23 \%$ of the variance. The second step of the regression model entered $(\log )$ estradiol $R^{2}=0.499, F_{\text {inc }}(1,20)$ $=10.4, p<0.01$, which accounted for an additional $26 \%$ of the variance. No additional variables were entered into the equation. For the dependent variable of Stroop test change from baseline, a measure of selective attention, $R$ was significantly different from zero after entry of one independent variable $(\log )$ estradiol $F(1,21)$ $=5.33, p<0.05$, which explained $20 \%$ of the variance. No additional variables were entered into the equation. For the dependent variable of Route test change from baseline, a measure of spatial memory, $R$ was significantly different from zero after entry of one independent variable IGF-I $F(1,21)=9.85, p<0.01$, which explained $32 \%$ of the variance. No additional variables were entered into the equation. Education was not entered as a significant predictor in any of the regression models.

The individual regression models confirmed our findings from the Canonical Correlation analysis such that change from baseline levels of (square root) $\mathrm{T}$ and $(\log$ ) estradiol accounted for a significant amount of the variance for change from baseline in spatial reasoning performance (Block design), and change from baseline levels of 
(log) estradiol accounted for a significant amount of the variance for change from baseline performance on a task of divided attention (Stroop), and change from baseline levels of IGF-I accounted for a significant amount of the variance for change in performance on a task of spatial memory (Route test). Partial correlation coefficients for regression models that were significant are included in Table 3. The results from the individual regression equations suggest that $\mathrm{T}$, estradiol and IGF-I have unique, and somewhat independent contributions to cognitive functioning.

\section{Discussion}

The first aim of this study was to examine if $\mathrm{T}$ supplementation resulted in changes in IGF-I, IGF-II and related IGFBP levels in a population of older men. Androgen effects on IGF-I levels and the somatropic axis have been reported in both young and old men (Ferrando et al., 2002; Hobbs et al., 1993; Veldhuis et al., 1997; Weissberger and Ho, 1993). Our results indicate a significant interaction effect of IGF-I levels between the treatment and placebo group. This interaction effect was due to an increase in IGF-I levels in the treatment group and a decrease in the placebo group. However, these changes were not significantly different from baseline levels. Although the increase in the treatment group may represent an effect from androgen treatment, due to the concomitant significant drop in the placebo group, we cannot confidently conclude that this is an androgen effect. Although previous studies have reported increased IGF-I levels in young and older men from $\mathrm{T}$ treatment, the dosage of $\mathrm{T}$ used in those studies was much higher (e.g. T enanthate 300 $600 \mathrm{mg}$ weekly) or treatment continued for a longer period of time than the present study (e.g. 4-6 months) (Bhasin et al., 2001; Ferrando et al., 2002; Hobbs et al., 1993).

A second aim of this study was to determine the relationship between cognitive measures and hormones. Results of the canonical correlation analysis revealed

Table 3

Partial correlation coefficients between change in serum hormone levels from baseline and change in cognitive test performance from baseline ${ }^{\mathrm{a}}$

\begin{tabular}{lccc}
\hline Independent variables & \multicolumn{2}{l}{ Regression model dependent variables } \\
\cline { 2 - 4 } & $\begin{array}{l}\text { Spatial reasoning } \\
\text { Block design }\end{array}$ & $\begin{array}{l}\text { Divided attention } \\
\text { Stroop test }\end{array}$ & $\begin{array}{l}\text { Spatial memory } \\
\text { Route test }\end{array}$ \\
\hline Education & 0.14 & -0.10 & 0.01 \\
Testosterone & $-0.69 * *$ & 0.15 & 0.02 \\
Estradiol & $0.58 * *$ & $0.45 *$ & -0.11 \\
IGF-I & 0.06 & 0.23 & $0.56 * *$ \\
IGF-II & 0.08 & 0.05 & -0.29 \\
\hline
\end{tabular}

$* * p<0.01, * p<0.05$.

${ }^{a}$ Results are reported for cognitive tests with significant Stepwise Regression Models. 
improved performance on measures of spatial memory, spatial ability and verbal fluency were positively associated with both IGF-I and IGF-II levels (Table 2). Several studies have reported significant positive correlations between endogenous serum IGF-I levels and cognition. Aleman et al. (1999) and van Dam et al. (2000) reported a positive relationship between endogenous IGF-I levels and cognitive processing speed and motor function in a group of healthy older men. A subsequent analysis on the same study sample, revealed a positive association between measures of fluid intelligence and endogenous IGF-I levels (Aleman et al., 2001). Several other studies have reported similar findings including positive correlations between MMSE scores (Rollero et al., 1998), the Digit Symbol Substitution Test a measure of processing speed (Papadakis et al., 1995), and the Rey Auditory Verbal Learning Test and Rey Visual Design Learning Test measures of memory (Morley et al., 1997) and endogenous IGF-I levels. Two studies examining changes in response to growth hormone releasing hormone $(\mathrm{GHRH})$ have reported a positive relationship between IGF-I levels and cognition but no relationship between GH response to GHRH and cognition. It is not clear from those studies if IGF-I levels changed significantly from baseline.

Our findings of positive associations between IGF-I and IGF-II levels and spatial and verbal memory during treatment are consistent with previous findings of positive associations between endogenous IGF-I levels and cognition. However, we cannot conclude that the positive association between IGF levels and cognition is related to androgen treatment as IGF-I, -II and IGFBP levels did not significantly change from baseline with $\mathrm{T}$ treatment.

Both the multivariate results of the canonical correlation and the subsequent stepwise multiple regression analysis support a specific relationship between IGF-I levels and memory measures. Both IGF-I and IGF-II peptides and their receptors are widely distributed through the brain but mainly concentrated in the choroids plexus, pituitary, hippocampus, putamen and hypothalamus (Goodyer et al., 1984; Kar et al., 1997). Thus, IGF-I and IGF-II may have specialized roles in the hippocampus, a brain structure that mediates memory. IGF-I receptor binding sites are recognized by IGF-I, IGF-II and insulin and are primarily located in the dentate gyrus and CA2CA3 subfields of the hippocampus. IGF-II receptors recognize IGF-II and IGF-I but not insulin and are localized predominantly in the pyramidal cell layer of CA1-CA3 and in the granular cell layer of the dentate gyrus (Kar et al., 1997). IGF-I and IGFII have been shown to potentiate ACh release from the hippocampus. IGF-I and II acting as modulators in the regulation of ACh release in the hippocampus is consistent with our findings of a strong association between IGF-I, IGF-II and declarative memory tasks (such as the spatial and verbal memory tasks used in the present study) and a weak association with divided attention, which is mediated by frontalsubcortical circuits. Thus our results are consistent with a possible specialized role of IGF-I and possibly IGF-II in hippocampally mediated tasks such as declarative memory and spatial abilities.

A strong positive association was found between increased $\mathrm{T}$ levels from baseline and improvement from baseline in spatial reasoning (Block design) performance. Despite numerous studies relating endogenous $\mathrm{T}$ levels with spatial abilities, a positive association between change in performance on a spatial reasoning task and 
change in $\mathrm{T}$ levels from treatment have not been previously reported. Studies of $\mathrm{T}$ supplementation in older men have reported no change in cognitive performance (Sih et al., 1997; Wolf et al., 2000) or improved spatial working memory (Janowsky et al., 1997, 2000). A recent study of $\mathrm{T}$ supplementation reported a decrease in performance on Block design in healthy young men but an improvement in hypogonadal and placebo treated men (O'Connor et al., 2001). While their results appear to be in contrast to our findings, there is no overlap between the studies with regard to the age range of participants and the dosage level used.

The relationship between androgens and cognition and the GH/IGF system is likely complex, and further complicated by aromatization of $\mathrm{T}$ into estradiol. Results of the canonical correlation analysis indicate that estradiol levels during treatment were positively associated with better verbal memory and negatively associated with divided attention. Similarly, results from the stepwise regression analysis indicated that increased estradiol levels from baseline was a significant predictor of a decline from baseline on a task of divided attention (Stroop test) and spatial reasoning (Block design). Although higher endogenous levels of estrogen are associated with faster motor movement and reaction time in women this relationship has not been observed in men (Jennings et al., 1998). Thus although the Stroop test and Block design are timed tasks, it is unlikely that our findings are due to a simple change in reaction time or motor movement. Our results of a negative association between estradiol and spatial reasoning are consistent with Janowsky et al. (2000) who reported increased estradiol levels negatively correlated with spatial working memory performance in $\mathrm{T}$ supplemented older men. Although the role of estrogen in cognitive functioning in men is currently unknown, a positive association between estradiol levels and verbal memory has been reported in estrogen treated male to female transsexuals (Miles et al., 1998). In women, estrogen treatment studies have reported findings of improved verbal memory and executive functions (Asthana et al., 1996, 1999; Duff and Hampson, 2000) although findings are mixed across studies (LeBlanc et al., 2001). The observed effect of estradiol on cognition in this study is likely an indirect effect of androgens via aromatization. Nonetheless, it appears that estrogen may influence cognitive abilities in men independent of androgens as estradiol, followed $\mathrm{T}$ as a significant predictor in the stepwise regression model and explained an additional $26 \%$ of the variance in spatial reasoning performance.

Our results indicate that $\mathrm{T}$ and estradiol levels changed significantly from baseline during treatment, whereas IGF-I levels did not. Thus, changes in divided attention and spatial reasoning are due to androgen treatment effects. It is less clear whether the significant relationship between change from baseline IGF-I levels and spatial memory reflects a treatment effect, as IGF-I levels did not change significantly from baseline. Most likely, the significant association between IGF-I and IGF-II levels and spatial memory is reflective of a positive relationship between endogenous IGFI levels and cognition. Additional studies are needed in which a significant change in IGF-I levels is found to be predictive of a significant change in cognition.

Due to our limited sample size, our results must be interpreted with caution. Independent replication of our results with a larger sample size are needed and will provide further evidence of the relationship between IGF's, androgens and cognition. 
Despite the limitations of our sample size, our results are consistent with previous findings supporting a positive relationship between IGF-1 levels and cognition and $\mathrm{T}$ levels and spatial reasoning. Our findings of a positive association between increased $\mathrm{T}$ levels and improved performance on a task of spatial reasoning and increased estradiol adversely effecting divided attention in men have not been previously reported. Additional studies that examine cognition in response to manipulation of IGF-I levels and corresponding IGFBPs will provide valuable information on the relationship between IGFs and human cognition.

In summary, we found significant positive associations between IGF-I, IGF-II and spatial memory, spatial reasoning, verbal fluency, and between estradiol and verbal memory were observed after 6 weeks of $\mathrm{T}$ administration in healthy older men. A significant negative association was found between estradiol levels and divided attention. In addition, change in $\mathrm{T}$ and estradiol levels from $\mathrm{T}$ treatment significantly predicted changes in spatial reasoning and divided attention performance. Although serum IGF-I levels increased in the treatment group, due to a concomitant drop in IGF-I levels in the placebo group, we cannot conclude that this change was due to $\mathrm{T}$ administration. Our results suggest that $\mathrm{T}$, estradiol and IGF-I may have independent and selective effects on cognitive functioning.

\section{Acknowledgements}

This research was supported by NIA \#AG00858 (Dr Cherrier). The Mellon Foundation and Department of Veterans Affairs, Merit Award (Dr Bremner), NIH (AR31062) (Dr P.I. Mohan).

\section{References}

Aleman, A., de Vries, W.R., de Haan, E.H., Verhaar, H.J., Samson, M.M, Koppeschaar, H.P., 2000. Agesensitive cognitive function, growth hormone and insulin-like growth factor 1 plasma levels in healthy older men. Neuropsychobiology 41, 73-78.

Aleman, A., de Vries, W.R., Koppeschaar, H.P., Osman-Dualeh, M., Verhaar, H.J., Samson, M.M., et al. 2001. Relationship between circulating levels of sex hormones and insulin-like growth factor-1 and fluid intelligence in older men. Exp. Aging Res. 27, 283-291.

Aleman, A., Verhaar, H.J., de Haan, E.H., de Vries, W.R., Samson, M.M., Drent, M.L., et al. 1999. Insulin-like growth factor-I and cognitive function in healthy older men. J. Clin. Endocrinol. Metab. $84,471-475$.

Alexander, G.M., Swerdloff, R.S., Wang, C., Davidson, T., McDonald, V., Steiner, B., et al. 1998. Androgen-behavior correlations in hypogonadal men and eugonadal men. II. Cognitive abilities. Horm. Behav. 33, 85-94.

Asthana, S., Craft, S., Baker, L.D., Raskind, M., Avery, E., Lofgren, C., et al. 1996. Transdermal estrogen improves memory in women with Alzheimer's disease. Soc. Neurosci. Abstr. 22, 200. 
Asthana, S., Craft, S., Baker, L.D., Raskind, M.A., Birnbaum, R.S., Lofgreen, C.P., et al. 1999. Cognitive and neuroendocrine response to transdermal estrogen in postmenopausal women with Alzheimer's disease: results of a placebo-controlled, double-blind, pilot study. Psychoneuroendocrinology 24, $657-677$.

Barrash, J., Tranel, D., 1996. Neuropsychological correlates of route learning. J. Int. Neuropsychol. Soc. $2,69$.

Benbassat, C.A., Maki, K.C., Unterman, T.G., 1997. Circulating levels of insulin-like growth factor (IGF) binding protein-1 and -3 in aging men: relationships to insulin, glucose, IGF, and dehydroepiandrosterone sulfate levels and anthropometric measures. J. Clin. Endocrinol. Metab. 82, 1484-1491.

Bhasin, S., Woodhouse, L., Casaburi, R., Singh, A.B., Bhasin, D., Berman, N., et al. 2001. Testosterone dose-response relationships in healthy young men. Am. J. Physiol. Endocrinol. Metab. 281, E1172-E1181.

Cherrier, M.M., Asthana, S., Baker, L.D., Plymate, S., Matsumoto, A., Peskind, E., et al. 2001. Exogenous testosterone administration in healthy older men effects spatial and verbal memory. Neurology 57, 80-88.

Craft, S., Dagogo-Jack, E., Wiethop, C.M., Nevins, R., Fleischman, S., Rice, V., et al. 1993. The effects of hyperglycemia on memory and hormone levels in dementia of the Alzheimer's type: a longitudinal study. Behav. Neurosci. 107, 926-941.

Craft, S., Murphy, C., Wemstrom, J., 1994. Glucose effects on memory and complex non-memory measures: the influence of age, sex, and glucoregulatory response. Psychobiology 22, 95-105.

Craft, S., Zallen, G., Baker, L.D., 1992. Glucose and memory in mild senile dementia of the Alzheimer type. J. Clin. Exp. Neuropsychol. 14, 253-267.

van Dam, P.S., Aleman, A., de Vries, W.R., Deijen, J.B., van der Veen, E.A., de Haan, E.H., et al. 2000. Growth hormone, insulin-like growth factor I and cognitive function in adults [in process citation]. Growth Horm. IGF Res. 10 (Suppl. B), S69-S73.

D’Costa, A.P., Xu, X., Ingram, R.L., Sonntag, W.E., 1995. Insulin-like growth factor-1 stimulation of protein synthesis is attenuated in cerebral cortex of aging rats. Neuroscience $65,805-813$.

Duff, S.J., Hampson, E., 2000. A beneficial effect of estrogen on working memory in postmenopausal women taking hormone replacement therapy. Horm. Behav. 38, 262-276.

Ferrando, A.A., Sheffield-Moore, M., Yeckel, C.W., Gilkison, C., Jiang, J., Achacosa, A., et al. 2002. Testosterone administration to older men improves muscle function: molecular and physiological mechanisms. Am. J. Physiol. Endocrinol. Metab. 282, E601-E607.

Folstein, M.F., Folstein, S.E., McHugh, P.R., 1975. Mini-mental state: a practical method for grading the cognitive state of patients for the clinician. J. Psychiatr. Res. 12, 189-198.

Goodyer, C.G., De Stephano, L., Lai, W.H., Guyda, H.J., Posner, B.I., 1984. Characterization of insulinlike growth factor receptors in rat anterior pituitary, hypothalamus, and brain. Endocrinology 114, 1187-1195.

Gori, F., Hofbauer, L.C., Conover, C.A., Khosla, S., 1999. Effects of androgens on the insulin-like growth factor system in an androgen-responsive human osteoblastic cell line. Endocrinology 140, 5579-5586.

Han, V.K., Lauder, J.M., D’Ercole, A.J., 1988. Rat astroglial somatomedin/insulin-like growth factor binding proteins: characterization and evidence of biologic function. J. Neurosci. 8, 3135-3143.

Hobbs, C.J., Plymate, S.R., Rosen, C.J., Adler, R.A., 1993. Testosterone administration increases insulinlike growth factor-I levels in normal men. J. Clin. Endocrinol. Metab. 77, 776-779.

Honda, Y., Landale, E.C., Strong, D.D., Baylink, D.J., Mohan, S., 1996. Development, validation, and application of a radioimmunoassay for IGFBP-4 in human serum and other biological fluids. J. Clin. Endocrinol. Metab. 81, 1389-1396.

Ishii, D.N., 1989. Relationship of insulin-like growth factor II gene expression in muscle to synaptogenesis. Proc. Natl. Acad. Sci. USA 86, 2898-2902.

Ishii, D.N., Glazner, G.W., Pu, S.F., 1994. Role of insulin-like growth factors in peripheral nerve regeneration. Pharmacol. Ther. 62, 125-144.

Janowsky, J., Chavez, B., Zamboni, B., Orwoll, E., 1998. The cognitive neuropsychology of sex hormones in men and women. Dev. Neuropsychol. 14, 421-440.

Janowsky, J., Orwoll, E., Chavez, B., 1997. Sex hormones affect working memory. In: Society for Neurosciences Abstracts, 23. Society for Neuroscience, New Orleans, LA, 775. 
Janowsky, J.S., Chavez, B., Orowoll, E., 2000. Sex steroids modify working memory. J. Cogn. Neurosci. $12,407-414$.

Janowsky, J.S., Oviatt, S.K., Orwoll, E.S., 1994. Testosterone influences spatial cognition in older men. Behav. Neurosci. 108, 325-332.

Jennings, P.J., Janowsky, J.S., Orwoll, E., 1998. Estrogen and sequential movement. Behav. Neurosci. 112, 154-159.

Kalmijn, S., Janssen, J., Pols, H., Lamberts, S., Breteler, M., 2000. A prospective study on circulatin insulin-like growth factor I (IGF-I), IGF-binding proteins and cognitive function in the elderly. J. Clin. Endocrinol. Metab. 85, 4551-4555.

Kar, S., Seto, D., Dore, S., Hanisch, U., Quirion, R., 1997. Insulin-like growth factors-I and -II differentially regulate endogenous acetylcholine release from the rat hippocampal formation. Proc. Natl. Acad. Sci. USA 94, 14054-14059.

Lai, M., Hibberd, C.J., Gluckman, P.D., Seckl, J.R., 2000. Reduced expression of insulin-like growth factor 1 messenger RNA in the hippocampus of aged rats. Neurosci. Lett. 288, 66-70.

Lai, Z., Roos, P., Zhai, O., Olsson, Y., Fholenhag, K., Larsson, C., et al. 1993. Age-related reduction of human growth hormone-binding sites in the human brain. Brain Res. 621, 260-266.

LeBlanc, E.S., Janowsky, J., Chan, B.K., Nelson, H.D., 2001. Hormone replacement therapy and cognition: systematic review and meta-analysis. JAMA 285, 1489-1499.

Lezak, M.D., 1995. Neuropsychologcial Assessment. third ed. Oxford University Press, New York, NY.

Matsumoto, A.M., 1996. The testis. In: Bennett, J.C., Plum, F. (Eds.), Cecil Textbook of Medicine. Saunders, Philadelphia, PA, pp. 1325-1341.

Mattis, S., 1988. Dementia Rating Scale. Psychological Assessment Resources, Inc., Odessa, FL.

McMorris, F.A., Dubois-Dalcq, M., 1988. Insulin-like growth factor I promotes cell proliferation and oligodendroglial commitment in rat glial progenitor cells developing in vitro. J. Neurosci. Res. 21, 199-209.

Miles, C., Green, R., Sanders, G., Hines, M., 1998. Estrogen and memory in a transsexual population. Horm. Behav. 34, 199-208.

Mohan, S., Baylink, D.J., 1995. Development of a simple valid method for the complete removal of insulin-like growth factor (IGF)-binding proteins from IGF's in human serum and other biological fluids: comparison with acid-ethanol treatment and $\mathrm{C}_{18}$ Sep-Pak separation. J. Clin. Endocrinol. Metab. 80, 637-647.

Mohan, S., Baylink, D.J., 1997. Serum insulin-like growth factor binding protein (IGFBP)-4 and IGFBP5 levels in aging and age-associated diseases. Endocrine 7, 87-91.

Mohan, S., Libanati, C.R., Dony, C., Lang, K., Srinivasan, N., Baylink, D.J., 1995. Development, validation, and application of a radioimmunoassay for insulin like growth fator binding protein-5 in human serum and other biological fluids. J. Clin. Endocrinol. Metab. 80, 2638-2645.

Morley, J.E., Kaiser, F., Raum, W.J., Perry, M., Flood, J.F., Jensen, J., et al. 1997. Potentially predictive and manipulable blood serum correlates of aging in the healthy human male: progessive decreases in bioavailable testosterone, dehydroepiandrosterone sulfate, and the ratio of insulin-like growth factor to 1 growth hormone. Proc. Natl. Acad. Sci. USA 94, 7537-7542.

O'Connor, D.B., Archer, J., Hair, W.M., Wu, F.C., 2001. Activational effects of testosterone on cognitive function in men. Neuropsychologia 39, 1385-1394.

Papadakis, M.A., Grady, D., Tierney, M.J., Black, D., Wells, L., Grunfeld, C., 1995. Insulin-like growth factor 1 and functional status in healthy older men. J. Am. Geriatr. Soc. 43, 1350-1355.

Recio-Pinto, E., Rechler, M.M., Ishii, D.N., 1986. Effects of insulin, insulin-like growth factor-II, and nerve growth factor on neurite formation and survival in cultured sympathetic and sensory neurons. J. Neurosci. 6, 1211-1219.

Rollero, A., Murialdo, G., Fonzi, S., Garrone, S., Gianelli, M.V., Gazzerro, E., et al. 1998. Relationship between cognitive function, growth hormone and insulin-like growth factor I plasma levels in aged subjects. Neuropsychobiology 38, 73-79.

Russo, V.C., Rekaris, G., McKean, S.C., Baker, N.L., Zajac, J.D., Werther, G.A., 1999. Type I Insulinlike Growth Factor (IGF) receptor is regulated by activation of the androgen receptor in human neuroblastoma cells. In: Endocrine Society Program and Abstracts, Program Number P2-612. The Endocrine Society Press, Bethesda, MD. 
Saatman, K.E., Contreras, P.C., Smith, D.H., Raghupathi, R., McDermott, K.L., Fernandez, S.C., et al. 1997. Insulin-like growth factor-1 (IGF-1) improves both neurological motor and cognitive outcome following experimental brain injury. Exp. Neurol. 147, 418-427.

Sih, R., Morley, J.E., Kaiser, F.E., Perry, H.M., Patrick, P., Ross, C., 1997. Testosterone replacement in older hypogonadal men: a 12 month randomized controlled trial. J. Clin. Endocrinol. Metab. 82, 1661-1667.

Snow, W.G., Tierney, M.C., Zorzitto, M.L., 1988. One-year test re-test reliability of selected neuropsychological tests in older adults. J. Clin. Exp. Neuropsychol. 10, 60.

Sonntag, W.E., Lynch, C.D., Cooney, P.T., Hutchins, P.M., 1997. Decreases in cerebral microvasculature with age are associated with the decline in growth hormone and insulin-like growth factor 1. Endocrinology 138, 3515-3520.

Spreen, O., Strauss, E., 1991. A Compendium of Neuropsychological Tests. Oxford University Press, New York, NY.

SPSS, I., 1998. SPSS for Windows, Version Release 9.0.0. SPSS, Inc., Chicago, IL.

Stroop, J.R., 1935. Studies of interference in serial verbal reactions. J. Exp. Psychol. 18, 643-662.

Tabachnik, B.G., Fidell, L.S., 1986. Using Multivariate Statistics, third ed. Harper \& Collins, New York, NY.

Veldhuis, J.D., Metzger, D.L., Martha, P.M. Jr., Mauras, N., Kerrigan, J.R., Keenan, B., et al. 1997. Estrogen and testosterone, but not a nonaromatizable androgen, direct network integration of the hypothalamo-somatotrope (growth hormone)_insulin-like growth factor I axis in the human: evidence from pubertal pathophysiology and sex-steroid hormone replacement. J. Clin. Endocrinol. Metab. 82, 3414-3420.

Vendola, K., Zhou, J., Wang, J., Bondy, C.A., 1999. Androgens promote insulin-like growth factor-I and insulin-like growth factor-I receptor gene expression in the primate ovary. Hum. Reprod. 14, 2328-2332.

Wechsler, D., 1981. Weschler Adult Intelligence Scale-Revised. The Psychological Corporation, San Antonio, TX.

Wechsler, D., 1987. Wechsler Memory Scale_-Revised. The Psychological Corporation, San Antonio, TX.

Wechsler, D., 1997a. WAIS-III Administration and Scoring Manual. The Psychological Corporation, San Antonio, TX.

Wechsler, D., 1997b. Wechsler Memory Scale III. The Psychological Corporation, San Antonio, TX.

Weissberger, A.J., Ho, K.K., 1993. Activation of the somatotropic axis by testosterone in adult males: evidence for the role of aromatization. J. Clin. Endocrinol. Metab. 76, 1407-1412.

Wolf, O., Pruet, R., Hellhammer, D.H., Kudielka, B.M., Schurmeyer, T.H., Kirschbaum, C., 2000. Testosterone and cognition in elderly men: a single testosterone injection blocks the practice effect in verbal fluency, but has no effect on spatial or verbal memory. Biol. Psychiatry 47, 650-654. 